\title{
An examination of interprofessional education in a pre-registration children's nursing course
}

Whiting L, Caldwell C, Akers E (2016) An examination of interprofessional education in a pre-registration children's nursing course.

Nursing Children and Young People. Date of submission: 2I December 2015; date of acceptance: 3 March 2016. doi: I0.7748/ncyp.20I6.e747

\section{Lisa Whiting}

Professional lead, children's nursing, University of Hertfordshire, Hatfield

\section{Chris Caldwell}

Dean of healthcare professions, Health Education England North Central and East London

\section{Elizabeth Akers}

Practice educator, Great Ormond Street Hospital for Children NHS Trust, London

\section{Correspondence}

l.whiting@herts.ac.uk

\section{Review}

This article has been subject to open peer review and has been checked for plagiarism using automated software

\section{Conflict of interest}

None declared

\section{Acknowledgement}

The study was commissioned and funded by Health Education England North Central and East London

\begin{abstract}
Aim This study set out to gain insight into views held by children's nursing students, lecturers and clinically based nurse mentors about interprofessional education (IPE).

Method A qualitative research design was undertaken. Small focus groups were held with pre-registration children's nursing students, and semi-structured interviews with university lecturers and clinically based nurse mentors to find out information about their understanding of IPE.

Findings Participants not only valued IPE, but they agreed that it had the potential to positively affect the care of children, young people and their families.

Conclusion It is important that professionals collaborate to ensure students receive high quality IPE learning experiences.

Keywords

child health, children's nursing, education, interprofessional education, mentors, students

THERE IS now an expectation that health professionals will be able to work interprofessionally to enhance patient care (Chan et al 2013). There is also agreement that interprofessional education (IPE) provides students across a range of professional groups with the opportunity to experience collaborative working that replicates, to a certain extent, life as a registered practitioner and embeds it into professional practice (Taanila et al 2006, Taylor et al 2008, Curran et al 2010, Machin and Jones 2014).

\section{Literature review}

The literature tends to focus on the higher education institution (HEI) angle, such as curriculum design and the relevance of IPE to practice (Clarke et al 2007, Taylor et al 2008). To further understand the position on IPE in a children's healthcare setting, Taylor et al (2008) undertook a knowledge review. They described HEIs as being 'risk averse', entrenched with traditions and they did not always implement recommendations. The authors made a strong case for developing a workforce conversant in interprofessional language and practice during their initial training and also provided an appreciation of some of the barriers that

exist for academic staff involved in the delivery of IPE modules.

There is a perception that nursing students have limited knowledge of IPE. However, Curran et al (2010) conducted a longitudinal study to specifically examine IPE in terms of student satisfaction and their attitudes towards it and to teamwork. Students in nursing, medicine, pharmacy and social work completed attitudinal scales and also gave open-ended feedback. Curran et al (2010) found that $54 \%$ of the 502 comments were in favour of IPE and indicated that it had been a useful experience.

A central tenet of IPE is that of collaboration among students and between healthcare professionals and families (Taanila et al 2006, Curran et al 2010). In seeking to develop collaborative skills as a key aspect of interprofessional working, Taanila et al (2006) explored collaboration from the perspective of nurses who studied a 'family-oriented interprofessional programme'. A key domain to be achieved within IPE relates to participants being able to demonstrate the skills, abilities and aptitudes for collaborative working, which is considered a key component of professional life. The programme took an innovative approach that involved the
\end{abstract}


co-design of aspects of the course with families, demonstrating their equal status and the value placed on their role in collaborative working with professionals.

While the available literature does provide some understanding of the challenges and benefits of IPE, no research has focused specifically on children's nursing.

\section{Aim}

The aim of this study was to gain insight into the perspectives of clinical nurses, students and lecturers to enhance IPE experiences for children's nursing students.

\section{Method}

The research was undertaken in MarchSeptember 2015 and examined the theory and practice elements of IPE in the pre-registration children's nursing programme at the University of Hertfordshire (UH).

It aimed to gain insight into the understanding and perceptions of children's nursing students, lecturers and clinically based nurse mentors about IPE and its potential effect on the care delivered to children, young people and families.

Students at UH are offered a 15 -credit academic module in their first and third years. The children's nursing students study alongside their peers in all four fields of nursing, as well as pharmacy, dietetics, diagnostic radiography, radiotherapy, foundation paramedics, paramedic science, physiotherapy and social work.

The lecturing team for the IPE modules includes academic staff across all professional groups. The number of students taking each module is large (typically 850 on the first-year module). Students are taught in a lecture theatre, but there are also cross-profession seminar groups of about 30-40 students. In addition, students undertake clinical experiences throughout the three years of their programme, where IPE is put into practice.

Exploratory work often draws on qualitative approaches (Stebbins 2001). Semi-structured interviews were conducted face to face with clinically based nurse mentors and $\mathrm{UH}$ lecturers who were involved in the delivery of at least one IPE undergraduate module. This approach gave participants an opportunity to talk about their experiences, while allowing the use of 'prompt' questions to maximise data collection. The nursing student participants were involved in small focus groups. This approach has the potential to yield more in-depth data because it can enhance interaction by providing a more relaxed environment for participants (Krueger and Casey 2015).

\section{Ethical considerations}

Ethical approval was gained from the UH health and human sciences ethics committee. All participants were sent information sheets and gave written informed consent. A pseudonym was allocated to each participant to maintain confidentiality.

\section{Data collection}

A purposive sampling technique was used to recruit participants most suited to the needs of the study (Polit and Beck 2011). Full details of the study were sent in an email to potential participants from each of three BSc children's nursing cohorts: September $2012(n=33)$, September 2013 ( $n=19)$; and September $2014(n=19)$. A total of seven students responded and three small focus groups were conducted (one for each academic year of the programme). Eighteen lecturers, who taught at least one of the two IPE modules, were invited by email to take part in a face-to-face semi-structured interview. Eight responded and interviews were undertaken with children's nurses $(n=2)$, midwives $(n=2)$, a radiotherapist $(n=1)$, radiographer $(n=1)$, dietician $(n=1)$, and social worker $(n=1)$.

The lead for clinical governance at an NHS trust where the students do their placements granted approval for clinically based nurse mentors to be approached for the study. They were invited by email to take part in a face-to-face semi-structured interview. A total of 3 respondents accepted the invitation: 1 neonatal nurse and 2 children's nurses.

The lecturer interviews and small focus groups were conducted at the university; the interviews with clinically based nurse mentors were held at their workplaces. The focus groups lasted 55-58 minutes and the interviews were 27-57 minutes. All data collection and correspondence with participants was undertaken by one member of the research team to ensure consistency.

\section{Analysis}

A thematic approach was used for data analysis to identify themes (Alhojailan 2012). Each data set was analysed in turn, using a 6-stage approach (Braun and Clarke 2006). Data analysis was undertaken by one member of the research team to maintain consistency. Participants' actual words were used when reporting the findings (Chiovitti and Piran 2003).
Write for us

journals.rcni.com/r/

ncyp-author-guidelines 


\section{Findings}

Children's nursing students

Following data analysis, 2 themes emerged

from the student transcripts:

» Learning from and about each other.

»IPE in clinical practice.

The 7 students most frequently cited the opportunity to meet and work with students from other professions, giving them further insight into roles and responsibilities:

'I thought it was good to meet other professionals and learn about where they fit in the healthcare system and how we will be integrated with them and how important it is to make the patient's journey a smooth, successful journey from start to finish' (Angie, second-year student).

Students spoke positively about how they had examined case studies and considered them from different professional perspectives. In addition, some suggested that the inclusion of midwifery and medical students would have been beneficial. Learning with peers affirmed to students that they had made the correct career choice, and there were comments about the establishment of their own professional identity.

Students also highlighted the opportunity to make other professions aware of what children's nursing encompassed:

'I think a lot of people are quite confused about the different kind of nursing you can do and how you can differentiate between learning disability and mental health, adult and children. We could all express exactly what our role is and, obviously, as children's nurses, we can care for people up to age 18' (Jennifer, second-year student).

While the IPE modules were seen as valuable, there was a feeling that in their practice placements students were able to see 'interprofessional working happening' (Angie, second-year student) and 'seeing it in practice makes it more real rather than sitting and talking about it' (Marie, third year student).

Examples of learning about interprofessional working were more normally gained by students spending time observing and shadowing professionals such as doctors, physiotherapists, dietitians, and speech and language therapists. While some of these experiences were initiated by the student, having a good mentor was seen as beneficial.

These experiences were not necessarily viewed as IPE, but rather generic learning.

'My mentor said: "Oh, do you want to spend a day with this person?" Or they've been talking about a profession and I say:

"Oh, would I be able to spend some time with them?"' (Alison, first-year student).
Clinical practice provided opportunities to see things from the patient's perspective:

'I spent a day in a walk-in centre and I got to follow one specific patient around... actually being there, seeing how each professional works with each other helps to understand it all and how they all communicate with each other' (Alison, first-year student).

There was also a realisation that when professionals work together the whole family can benefit:

'I think it makes you think of the family as a whole rather than just the patient' (Chelsea, first-year student).

While most of the discussions about clinically-based interprofessional working were positive, the students described some negative experiences. These centred on procedures, such as an intravenous cannulation, that had not gone smoothly; these situations had an effect on students' learning and prompted reflection on how such scenarios could be avoided.

\section{Lecturers}

Four themes were identified from the semistructured interviews with lecturers:

» Participants' background and expertise.

» The content and delivery of the IPE modules.

»Applying IPE in clinical practice.

» Thinking about the way forward.

Participants had a range of professional backgrounds and expertise, and they had all been involved in delivering 1 or more IPE module for a minimum of two years. In terms of teaching IPE, there was general agreement that facilitation skills were pivotal for building a rapport with students; it was also vital that people had equal opportunities to express their views and to ensure that group work was appropriate. As a result, comments were made about the need to have more experienced lecturers on the module team.

The lecturers were in agreement with the students who participated in the focus groups on the point that students benefited from studying with peers from other professional groups. Otherwise, according to one participating social work lecturer, they could have 'misconceptions about what others do'.

'I think they understand more fully radiographers' roles and the physiotherapy role. They are much more willing to say: "May I stay with you while you're doing chest physio on this child?" Or "When you were doing the assessment, why did you say that about their clinical situation?" in a way which they wouldn't have done had those initial barriers not been broken down' (Isobel, children's nursing lecturer). 
The lecturers spoke of the 'professional pride' exhibited by the different groups of students, highlighting that this could, at times, lead to challenging classroom discussions that needed to be addressed. There was consistent opinion from lecturers that it would be beneficial to involve other professional groups, such as medical students, in the IPE modules, echoing the findings from the focus groups.

All lecturers mentioned the benefits of embedding IPE in undergraduate programmes from an early stage to provide students with opportunities to explore issues such as confidentiality within a safe environment. There was agreement that students enjoyed considering care from the service user's perspective and that there was scope to develop such involvement. One said: 'It's very powerful to get service users to speak directly to the students' (Gemma, midwifery lecturer).

There was agreement that the 'ultimate aim of IPE is to provide quality care' (Danny, radiography lecturer), that clear links with practice were essential and that the role of the mentor was fundamental. The children's nursing lecturers commented that, as a result of IPE, students in clinical practice were more likely to suggest the referral of a child to another professional, and that this could only be beneficial to overall care. Lecturers from other professions felt the involvement of children's nursing lecturers in the IPE modules meant students from all professional groups developed insight into and knowledge of child healthcare:

'We discuss children with illnesses... and the impact of the way we treat them has on their families, how to communicate with children. It will certainly get all of our students to think about how they interact with children and the importance of engaging with the child and not just the adult' (Helena, radiotherapy lecturer).

The lecturers had suggestions about how IPE could be developed further with participants mentioning 'buddy' schemes, mentoring across professions and the use of simulation.

\section{Clinical nurses}

Two themes emerged from the semi-structured interviews with clinical nurses:

»Professional background and expertise.

» Facilitation of IPE in clinical practice: learning from each other.

The three nurses had a breadth of clinical experience, having been registered with the Nursing and Midwifery Council for between 25 and 36 years. All of them were mentors to children's nursing students. During their own nursing programmes, none had undertaken
Box I: Interprofessional education activities organised by lecturers for students

Attendance at multiprofessional meetings

Involvement in a ward round

»Arranging for students to follow a child through their healthcare journey

Visits to different departments, such as the operating theatre or a clinic

» Spending time with another professional, such as a physiotherapist, doctor, occupational therapist or dietitian

» Training days

specific IPE modules. However, they felt they had learned interprofessionally and appreciated the value of this once they had qualified. This, in turn, had positively influenced the IPE opportunities they now offered students.

All participants had a good understanding of IPE. The nurses emphasised the value of learning about the roles of other professionals, explaining that patients benefitted from a collaborative approach. There was agreement that the facilitation of student learning implicitly meant the inclusion of IPE opportunities.

While they appreciated the advantages of studying the IPE modules, there was agreement that learning in, and from, practice was crucial and that it was an opportunity to apply theory to practice:

'It is good to help the students to bridge the theory and practice gap. That's where we come in' (Juliette, senior sister).

The role of the mentor to facilitate student learning was clearly recognised, and all participants identified a comprehensive range of IPE activities they organised for students (Box 1).

'It could be attending free seminar sessions that are happening in the environment, or it could be using a case study and reflecting back to a patient that they are looking after. There are learning opportunities everywhere' (Juliette, senior sister).

There was agreement about the value of meeting other members of the multiprofessional team and learning from them. All nurse participants mentioned the importance of learning about the roles and responsibilities of doctors, concurring with the findings from the focus groups with students and interviews with lecturers:

'One student who went to theatre... was reeling from what they'd done in theatre. It was an appendectomy and she was quite in awe of seeing it, and understanding and looking at the biology of it, looking at the way the surgeon carried out his job, and then she was able to apply it to the post-op care' (Emily, senior staff nurse).

The nurses provided opportunities for students to express their learning needs and 
they tried to meet these. One participant gave an example of students requesting more information about caring for children with respiratory problems, so a talk and a demonstration of oronasopharyngeal suctioning was organised and the students practised on a child-size manikin. The concept of simulation and role play was highlighted as important because it enhanced application to practice.

While a range of IPE opportunities were available for students during their clinical experiences, this was not 'labelled' as such 'it's just a training session' (Penny, sister and education facilitator). Senior staff nurse Emily said: 'I'd call it education. I would just say it's learning skills and it's broadening your horizons'.

All participants were able to give clear examples from their practice of occasions when communication had worked well and when it had broken down. This was felt to be a valuable IPE learning opportunity. Aligned with this was the need for students to appreciate that they are part of a team, liaising with other professionals for the benefit of the child and family.

\section{Discussion}

Previous UK-based studies have not focused on the perceptions of IPE of students, lecturers and clinically based nurse mentors within the same study and in children's nursing. This research provided valuable insight into the subject and revealed a number of findings essential for successful IPE implementation: most notably, that it is crucial to have a clear interface between theory and practice.

First, the findings show that clinically based nurses have much to offer in terms of facilitating IPE. They have the knowledge, skills and abilities to ensure students can take advantage of learning opportunities within the 'real' world of practice.

All students acknowledged the key role played by their mentors - it is therefore important that the potential for IPE in practice settings is acknowledged and that mentors are given the necessary support to further facilitate this.

Second, the study revealed that the lecturer role is fundamental for the support of student learning. Clarke et al (2007) highlighted the complexity of group work in IPE and described the importance of facilitation by managing group dynamics, conflict and ensuring inclusiveness. It is, therefore, imperative to ensure that lecturers involved in IPE delivery have appropriate preparation.
The focus groups revealed that students not only learned about other professional groups, but that IPE helped them develop their own professional identity. Authors, such as Morison and Jenkins (2007), suggest that this is central to IPE. Reflecting on how and when IPE is delivered could be crucial since the establishment of professional identity is important in terms of the student's receptiveness to learning with peers from other disciplines.

While all pre-registration children's nursing students are now required to study at degree level or higher, nursing remains primarily a practice-based profession, so the links with classroom-taught IPE must be directly related to clinical practice. One important point that emerged from the study was the potential to draw more extensively on role-play and simulated practice. While this approach can be labour intensive and time consuming, Davies (2015) reminds us that active learning of this nature can mean that as much as $90 \%$ of information will be retained.

\section{Limitations and future work}

It is important to acknowledge the limitations of this study. Students who responded to the invitation to participate may have done so because they had a specific interest in IPE. In addition, the sample sizes across all participant groups were small, so the findings may not be fully representative. Nonetheless, the study data indicate areas that would merit further investigation:

» Further examination of IPE undertaken by children's nursing students in clinical practice.

»Consideration of the support and information necessary for clinically based nurse mentors to further facilitate IPE in clinical settings.

» More detailed exploration of the effects of IPE and its influence on the day-today clinical practice of children's nursing students.

\section{Conclusion}

The research confirms that children's nursing students, lecturing staff and clinically based nurses all value IPE and concur that it has the potential to have a positive effect on the care of children and young people. However, it is important that the main underpinning principles are in place.

At UH, a review of IPE is being undertaken to enhance the student experience. First, from September 2016, the first-year IPE module will be relocated to within each professional 
programme. This means that students will undertake some study just with peers from their own discipline, therefore allowing them to establish their professional identity. There will, however, also be the inclusion of some cross-disciplinary teaching sessions so that students develop an awareness of the roles and responsibilities of others.

The third-year IPE module will remain generic and will provide opportunities for students across the professional groups to undertake IPE together. This is likely to culminate in a conference-style event where students present posters.

Second, a review of the timetable content and delivery, as well as assessments, has been carried out and is due to be implemented from September 2016. The changes will help to ensure students fully understand the main principles of IPE.

Finally, discussions are in place to identify how service users and clinicians can be involved more fully to enable the links with practice to be more overt.

IPE has been described by the World Health Organization (WHO) as 'essential to the development of a "collaborative practiceready" health workforce, one in which staff work together to provide comprehensive services in a wide range of healthcare settings' (WHO 2010). This study has provided insight into IPE from a children's nursing student perspective. The IPE review at UH has aimed to ensure that lecturers, practitioners and students work together to achieve the WHO goal.

(8)

\section{Implications for practice}

"Interprofessional education is an important aspect of clinical practice

» Nurse mentors play a key role in facilitating IPE opportunities in the clinical environment

» Nursing lecturers' skills underpin good facilitation
Online archive

For related information, visit our online archive and search using the keywords

\section{References}

Alhojailan MI (2012) Thematic analysis: a critica review of its process and evaluation. West East Journal of Social Sciences. 1, 1, 39-47.

Braun V, Clarke V (2006) Using thematic analysis in psychology. Qualitative Research in Psychology. $3,2,77-101$.

Chan EA, Lam W, Lam Yeung SK (2013) Interprofessional competence: a qualitative exploration of social work and nursing students experience. Journal of Nursing Education. 52, 9, 509-515.

Chiovitti RF, Piran N (2003) Rigour and grounded theory research. Journal of Advanced Nursing. $44,4,427-435$.
Clarke BA, Miers M, Pollard C et al (2007) Complexities of learning together: student's experience of face-to-face interprofessional groups. Learning in Health and Social Care. 6, 4, 202-212.

Curran VR, Sharpe D, Flynn K et al (2010) A longitudinal study of the effects of an interprofessional education curriculum on student satisfaction and attitudes towards interprofessional teamwork and education. Journal of Interprofessional Care. 24, 1, 41-52.

Davies N (2015) It pays to maximise your learning power. Nursing Standard. 30, 1, 66

Krueger RA, Casey MA (2015) Focus Groups. A Practical Guide for Applied Research. 5th edition. Sage Publications, Thousand Oaks CA.
Machin Al, Jones D (2014) Interprofessional service improvement learning and patient safety: a content analysis of pre-registration students' assessments. Nurse Education Today. 34, 2, 218-224.

Morison S, Jenkins J (2007) Sustained effects of interprofessional shared learning on student attitudes to communication and team working depend on shared learning opportunities on clinica placement as well as in the classroom. Medical Teacher. 29, 5, 464-470.

Polit DF, Beck CT (2011) Nursing Research Generating and Assessing Evidence for Nursing Practice. 9th edition. Lippincott Williams and Wilkins, Philadelphia PA.
Taanila A, Purola H, Larivaara P (2006) Nurses learning family-oriented interprofessional collaboration. International Journal of Circumpolar Health. 65, 3, 206-218

Taylor I, Sharland E, Whiting R (2008) Building capacity for the children's workforce: findings from the knowledge review of the higher education response. Learning in Health and Social Care. 7, 4, 184-197.

World Health Organization (2010) Framework for Action on Interprofessional Education \& Collaborative Practice. http://apps.who.int/iris/ bitstream/10665/70185/1/WHO_HRH_HPN_10.3_ eng.pdf (Last accessed: June 10 2016.) 